\title{
Study of Atmospheric Particulates' Fractal Feature Based on Fractal Combined with Bior 3.7 Wavelet
}

\author{
Yan Wang ${ }^{1,2, a},{ }^{*}$ Xuezhen Cheng ${ }^{1,2, b}$, Peng Wang ${ }^{1,2}$, Aying Wei $^{1,2}$ \\ ${ }^{1}$ College of Electrical Engineering and Automation Shandong University of Science and Technology, \\ Qingdao, 266590 \\ ${ }^{2}$ State Key Laboratory of Mining Disaster Prevention and Control Co-founded by Shandong \\ Province and the Ministry of Science and Technology, Qingdao, 266590

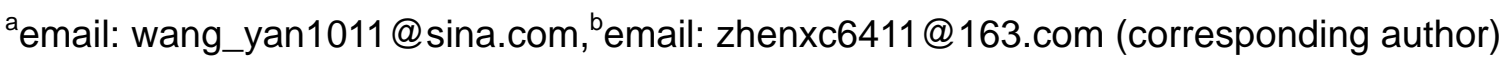

\section{Keywords: Atmospheric Particulates; Bior 3.7 Wavelet; Fractal Feature}

\begin{abstract}
A method based on fractal combined with Bior 3.7 wavelet is proposed to analyze atmospheric particulates' fractal feature. By the use of microscope, atmospheric particulate samples were taken into digital images. After a series of image processing including Bior 3.7 wavelet decomposition and reconstruction, and fractal-dimension calculation. Results indicate that: There is a inverse relation between particulates' fractal dimension and grain size. Larger the fractal dimension of particulate is, the higher content of fine particulate matter it will have; Smaller the particulate's fractal dimension is, greater its degree of sphericility is and smaller its specific surface area is; To a higher level's detail signal of atmospheric particulates, the fractal dimension of this detail signal turns small. What's more, the $\mathrm{H}$ signal, $\mathrm{V}$ signal and $\mathrm{D}$ signal are the same as atmospheric particulates' detail signal. So, higher level's detail signal of atmospheric particulates includes more large diameter particles
\end{abstract}

\section{Introduction}

Fractal has five basic characteristics: self-similarity, the tractability of structure, the irregularity of form, the iteration of generation, and the non-integer of dimension ${ }^{[1]}$. Because of the shape of environmental system is irregular and has the characteristic of random variation ${ }^{[2]}$, the fractal theory is applied in the study on the particulate matters in recent years ${ }^{[3-5]}$. YANG Jing .etc analyzed and studied the fractal characteristics of coal dust, and determined the relationship between the fractal dimension and the average grain size based on the laser grain size tester ${ }^{[6]}$. With MIP mercury intrusion test, HAN Ping .etc calculated and compared the fractal dimensions of cement-based materials in different shapes under different stress ${ }^{[7]}$. XIE Xianjian .etc studied the fractal dimension variation characteristics of waterstable aqqreqate under different eucalyptus grandis plantations, and analyzed the relationship between fractal dimension and soil properties ${ }^{[8]}$. The above researches discussed fractal characteristics for single particle, and seldom further analyzed image information. There is a profound intrinsic relationship between fractal geometry and wavelet transform ${ }^{[9]}$, so the microscopic image' fractal feature of atmospheric particulates collected from mainly related areas of Huangdao district is analyzed with the use of Bior 3.7 wavelet.

\section{The Experimental Results and Discussion}

Based on Matlab 7.0 environment, firstly the particulate matter digital image collected through a microscope was read into a tow-dimensional array; Secondly the image was grayed, and was decomposed into three levels by the use of Bior 3.7, then its detail signals were collected; Finally the detail signal's fractal dimension was calculated.

9 particulate samples are kitchen dust, road dust, biological incineration particulates, sea salt, coal dust, automobile exhaust, lime, cement, and soil. Their feature dimension and three levels' feature dimension are shown in Table 1. 9 samples' physical information (grain size, degree of sphericility, and specific surface area) is shown in Table 2 . The detail signals' fractal dimensions are 
shown in Table 3. In Table 3, H1: the first-level horizontal detail signal, V1: the first-level vertical detail signal, D1: the first-level diagonal detail signal; H2: the second-level horizontal detail signal, V2: the second-level vertical detail signal, D2: the second-level diagonal detail signal; H3: the third-level horizontal detail signal, V3: the third-level vertical detail signal, D3: the third-level diagonal detail signal.

Table 1 fractal dimension of particulate matter

\begin{tabular}{ccccc}
\hline & Fractal dimension & \multicolumn{3}{c}{ Fractal dimension of detail signal } \\
\cline { 3 - 5 } & & First level & Second level & Third level \\
\hline Coal dust & 2.1271 & 2.0967 & 2.0935 & 2.0809 \\
\hline Kitchen dust & 2.1574 & 2.1330 & 2.1193 & 2.1043 \\
\hline Sea salt & 2.3026 & 2.2193 & 2.2051 & 2.1846 \\
\hline Automobile exhaust & 2.1959 & 2.1532 & 2.1275 & 2.1154 \\
\hline Biological incineration particulates & 2.1400 & 2.1249 & 2.0839 & 2.0721 \\
\hline Lime & 2.2004 & 2.1492 & 2.1328 & 2.1185 \\
\hline Sement & 2.1210 & 2.1064 & 2.0665 & 2.0550 \\
\hline Road dust & 2.0935 & 2.0784 & 2.0716 & 2.0427 \\
\hline
\end{tabular}

Table 2 physical information of particulate matter

\begin{tabular}{cccc}
\hline & $\begin{array}{c}\text { Grain size } \\
(\mu \mathrm{m})\end{array}$ & $\begin{array}{c}\text { Degree of } \\
\text { sphericility }\end{array}$ & $\begin{array}{c}\text { Specific surface area } \\
\left(\mathrm{cm}^{2} / \mathrm{g}\right)\end{array}$ \\
\hline Coal dust & 8.5 & 0.850 & 267.119 \\
\hline Kitchen dust & 6.9 & 0.829 & 275.907 \\
\hline Sea salt & 3.8 & 0.803 & 833.541 \\
\hline Automobile exhaust & 4.6 & 0.820 & 275.868 \\
\hline Biological incineration particulates & 7.7 & 0.849 & 521.030 \\
\hline Lime & 4.0 & 0.819 & 251.497 \\
\hline Soment & 9.6 & 0.851 & 238.094 \\
\hline
\end{tabular}

Table 3 fractal dimension of particulate matte’s detail signal

\begin{tabular}{cccccccccc}
\hline & \multicolumn{10}{c}{ Fractal dimension } \\
\hline & H1 & V1 & D1 & H2 & V2 & D2 & H3 & V3 & D3 \\
\hline Coal dust & 2.0905 & 2.0996 & 2.1001 & 2.0873 & 2.0940 & 2.0991 & 2.0881 & 2.0849 & 2.0697 \\
\hline Kitchen dust & 2.1320 & 2.1306 & 2.1364 & 2.1013 & 2.1291 & 2.1276 & 2.1006 & 2.1211 & 2.0904 \\
\hline Sea salt & 2.2122 & 2.2443 & 2.2015 & 2.2068 & 2.2110 & 2.1976 & 2.1734 & 2.2022 & 2.1447 \\
\hline $\begin{array}{c}\text { Automobile } \\
\text { exhaust }\end{array}$ & 2.1445 & 2.1778 & 2.1373 & 2.1243 & 2.1283 & 2.1300 & 2.1177 & 2.1242 & 2.1001 \\
\hline $\begin{array}{c}\text { Biological } \\
\text { incineration } \\
\text { particulates }\end{array}$ & 2.1304 & 2.1476 & 2.0968 & 2.0800 & 2.0956 & 2.0762 & 2.0656 & 2.0744 & 2.0717 \\
\hline Lime & 2.1375 & 2.1814 & 2.1286 & 2.1311 & 2.1476 & 2.1198 & 2.1282 & 2.1356 & 2.0887 \\
\hline Cement & 2.1127 & 2.1259 & 2.0805 & 2.0681 & 2.0654 & 2.0660 & 2.0541 & 2.0499 & 2.0609 \\
\hline Soil & 2.0722 & 2.0831 & 2.0800 & 2.0700 & 2.0747 & 2.0702 & 2.0355 & 2.0545 & 2.0381 \\
\hline Road dust & 2.0646 & 2.0638 & 2.0532 & 2.0420 & 2.0486 & 2.0524 & 2.0330 & 2.0454 & 2.0385 \\
\hline
\end{tabular}


According to the Table 1 and Table 2, the fractal dimension and the physical information of particulate matters were compared. And road dust grain size was slightly larger than the others, so this parameter was not in the discussion. Through quantitative comparison, we found that with the increasing of grain size, the fractal dimension decreased. As the degree of sphericity increased, the fractal dimension showed a fall trend. With the increasing of fractal dimension, the specific surface area increased.

According to the Table 1 and Table 3, the fractal dimensions of three-level detail signals were analyzed. We found that: the fractal dimension of first-level detail signal was bigger than that of second-level detail signal, and the fractal dimension of second-level detail signal was bigger than that of third-level detail signal; The fractal dimension of $\mathrm{H} 1$ signal was bigger than that of $\mathrm{H} 2$ signal, and the fractal dimension of $\mathrm{H} 2$ signal was bigger than that of $\mathrm{H} 3$ signal; The fractal dimension of V1 signal was bigger than that of V2 signal, and the fractal dimension of V2 signal was bigger than that of V3 signal; The fractal dimension of D1 signal was bigger than that of D2 signal, and the fractal dimension of D2 signal was bigger than that of D3 signal. It showed that the same-type detail signal's fractal dimension between levels also complied with the law of first level's is bigger than the second level's, and the second level's is bigger than the third levels.

\section{Conclusion}

1. There is a inverse relation between particulates' fractal dimension and grain size. Larger the fractal dimension of particulate is, the higher content of fine particulate matter it will have.

2. Smaller the particulate's fractal dimension is, greater its degree of sphericility is and smaller its specific surface area is.

3. To a higher level's detail signal of atmospheric particulates, the fractal dimension of this detail signal turns small. What's more, the $\mathrm{H}$ signal, $\mathrm{V}$ signal and $\mathrm{D}$ signal are the same as atmospheric particulates' detail signal. So, higher level's detail signal of atmospheric particulates includes more large diameter particles.

\section{Acknowledgement}

In this paper, the research was sponsored by the Major Program of the National Natural Science Foundation of China (Grant No. U1261205), Shandong Province Large Scientific Instruments and Equipment Upgrade Program(No.2013SJGZ05), People's Livelihood Project of Huangdao District of Qingdao(No.2014-2-29), The Science and Technology Innovation Foundation for Graduate Student of Shandong University of Science and Technology(No. YC140339)

\section{References}

[1] CHENG Xue-zhen, CAO Mao-yong, Xu Xiao-ping. Comparative study of some description method of natural scenery based on fractal [J]. Computer Engineering and Design, 2008, 29(2):389-391.

[2] CHENG Xue-zhen, CAO Mao-yong, Xu Xiao-ping. Study of Description Method of Natural Scenery Based on Fractal [J]. Journal of System Simulation, 2007, 19(21):4957-4964.

[3] SHEN Rong-rong, et al. The Study on Fractal Dimensions of Size Distribution of Airborne Inhalable Particulates $\left(\mathrm{PM}_{10}\right)$ in Macao [J]. Environmental Monitoring in China, 2009, 25(6):74-77.

[4] YAN Jin-pei, YANG Lin-jun, FAN Feng-xian, et al. Numerical Analysis of Water Vapor Nucleation on Fine Particles From Coal Combustion Based on Fractal Model [J]. Proceeding of the CSEE, 2009, 29(11):50-56.

[5] HU Dawei, WANG Yanmin, YU Aizhi. Micro-outline Fractal and Origin Analysis of Atmospheric Particles [J]. China Powder Science and Technology, 2012,18(4):27-31.

[6] YANG Jing, WU Xiu-kun, Li Gai-ping, et al. Study on the Fractal Characteristics for Particle 
Sizes of Coal Dusts [J]. Journal of Shandong University of Science and Technology (Natural Science), 2010,29(1):31-36.

[7] HAN Ping, HAN Jiande, Wang Shuguang, etc. Influence of load and specimen shape on pore structure fractal feature of cement-based material in the carbonation reaction [J].Concrete, 2014, (8):57-73.

[8] XIE Xianjian, HAN Guangzhong.The analysis of fractal feature and corrosion stability of soil under different eucalyptus grandis plantations [J]. Soils, 46 (4) :725-731.

[9] TIAN Jie, CHEN Jie, ZHANG Yu-he. Target Detection and Recognition Based on Wavelet Transform and Fractal Features [J]. Transactions of Beijing Institute of Technology, 2003, 23(1):95-99. 